\title{
O papel da monitoria de comunicação clínica e raciocínio clínico-epidemiológico no desenvolvimento das relações médico-paciente
}

Gislaine Rosa de Souza Oliveira, Alice Ferraz Campos, Mariana Maia de Faria, Rafaella Rêllo Pinto Coelho Carvalho, Thais Souza Santos, Ticiana Moura Rosa Brandão

\section{Resumo}

A entrevista clínica centrada na pessoa foge à tradicional forma de construção da clínica médica, focada exclusivamente no diagnóstico e na conduta. Essa abordagem visa a um encontro menos diretivo, permitindo que o paciente tome parte na condução da entrevista e na escolha do tratamento. Prioriza-se então a pessoa, não a doença. O espaço da monitoria 'Comunicação clínica e raciocínio clínico-epidemiológico aplicados à prática médica", eixo das disciplinas Prática Profissional de Trabalho em Saúde III e IV, do curso de Medicina da Universidade Federal de Viçosa tem como função principal estender a aprendizagem das aulas para compartilhamento de experiências e treinamento das ferramentas aprendidas em sala de aula. A monitoria torna-se uma etapa na busca da empatia e construção de vínculo e confiança nas consultas médicas. É a segunda fase no processo de aprendizagem da Comunicação Clínica, sendo a primeira a sala de aula e a terceira e última, os cenários de prática. Várias técnicas são ensinadas para que sejam utilizadas em diferentes momentos da consulta clínica de forma a aproximar o paciente, melhorar a relação e poder, assim, colher mais informações e transmitir melhores resultados clínicos. Algumas dessas técnicas são denominadas a partir de acrônimos ou siglas, como o ETACCT, utilizado para abordar a experiência que o paciente tem de sua doença; o SIFE, utilizado para abordar emoções e reações demonstradas durante a consulta, de forma a desenvolver a empatia dos estudantes para com seus pacientes; o TRP, Terapia de Resolução de Problemas, utilizado para abordar e criar soluções práticas em conjunto com o paciente a fim de melhorar e resolver problemas de ordem social e/ou psicológica; o Plano Breve de Ação, que orienta a criação de metas junto ao paciente para mudanças de estilo de vida, hábitos e melhorar a adesão ao tratamento. Ao fim dos ciclos de estudos teóricos e práticos realizados pelos estudantes, estes são submetidos à uma avaliação prática de caráter não punitivo, em forma de dramatização na qual o estudante assume papel do médico, se houve o desenvolvimento das competências que guiam o atendimento centrado na pessoa. Após a realização da prova os estudantes recebem um retorno crítico da sua entrevista e é convidado a refletir sobre sua adequação ao modelo de atendimento e sua relevância. A inabilidade comunicativa que rege parte das consultas médicas nos tempos atuais é um dos motivos pelos quais muitas vezes a população se distancia do sistema de saúde e do seu bem-estar, e esse é um problema que questionamos enquanto participantes ativos da nossa formação. Por isso, trabalhamos para desenvolver com esses estudantes uma de abordagem que os ajude a construírem-se tanto médicos enquanto pessoas.

Descritores: Paciente; Exame Clínico; Trabalho 